\title{
The Rise of Apparatgeist and Its Implication for Media Convergence
}

\author{
Chen $\mathrm{LI}^{1, \mathrm{a},{ }^{*}}$ \\ ${ }^{1}$ School of International Communications, Beijing International Studies University, Chaoyang \\ District, Beijing, P.R. China, 100024 \\ akirbychenli@glasgowalumni.net \\ ${ }^{*}$ Corresponding author
}

\section{Keywords: Apparatgeist, Personal Communication Technologies, Media Convergence}

\begin{abstract}
This paper discusses the interaction between technology and society by referring to the concept "apparatgeist" (literally means "spirit of machines") raised by Katz and Aakhus [1]. Based on a critical review of relevant social theories, this paper aims to explore the socio-logic in the technological development as well as the changing context for "perpetual contact". It also shows its impact on the media convergence by assessing how mass media can be shaped.
\end{abstract}

\section{Introduction}

A neologism of "apparatgeist" was firstly proposed by Katz and Aakhus, deriving from a cross-national empirical study of the role played by the mobile phone in people's social lives [1]. Combined with "apparat" and "geist", "apparatgeist" literally means "spirit of machines", i.e. Technology itself tends to assume certain standard features independent of place or time. Based on this, they explored the role of Personal Communication Technologies (PCTs) in people's lives on the premise of perpetual contact, given the changing social and technological factors. For apparatgeist, the underlying logic of perpetual contact is based on the "pure communication" or "ideal communication", through which the values or effects of technologies can be explored [2].

\section{Reasoning, Patterns and Actors}

When it comes to the interaction between technology and society, the "hen and egg" dispute of which one to determine the other never stops. Some social theorists argue that "technological determinism" completely ignores human agency or meaning. For example, Silverstone regards technologies as both "enabling" and "disabling" factors rather than "their own making", and thus technologies are recreated in the interest of people [3]. To echo with this, Katz and Aakhus articulates the technology as "a constraint upon possibilities", which historically offers "identifiable, consistent and generalized" patterns of technological advancement for people to choose [1]. In other words, information and communication technologies (ICTs), from a functional perspective, have a feature of "dual-quality": both generating empirical predictions and formulating normative judgments.

Based on the idea of phenomenology, Heidegger argues that technologies can be rendered "invisible" on the grounds of being institutionalized [4].The ex-CEO of Hewlett Packard agrees with this by stating "technology, by 2030, will almost disappear as it is woven into the fabric of life in everything and everywhere" [5]. The reason why technology can be taken for granted in this way lies on the fact that people own a large amount of prior evaluation and resolved choices. In other words, both the function of technology and people's social status (e.g. roles, values) should be emphasized. Indeed, apparatgeist should be explored not only on the changing process of social-technical contexts (as structurational theorists did), but also on the individual level in its relation to the ICTs. For example, Campbell and Russo through their empirical studies find social network membership significantly influenced perceptions and uses of mobile phones and the "reciprocal" relationship between the technology and people [6]. 


\section{Perpetual Contact as the Socio-Logic}

Those inherently consistent patterns about perceptions and uses of PCTs can be traced to the desire for pure communication, as the theory of apparatgeist explains. This can be easily understood as the mobile phone, for instance, strengthens social networks ties, enabling people to connect with others anytime as well as anywhere [7]. Rhetoric surrounding the promise of 'anytime, anywhere' communication has proved significantly salient, especially given the rise of mobile internet in recent years. Being able to reach others and be reached by others continuously has become the core part of these technologies. In this way, it brings us back to McLuhan's view of "technology as physique", say, as extensions of human physical and psychological capacity to act in this world [3]. On the basis of apparatgeist, Katz furthers a theory of "machines that becomes us" that machines can extend our presentations with physically integrated into body and clothes, like wearable devices developed in recent years [8].

Perpetual contact is a socio-logic derived from collective sense-making. As opposed to techno-logic, the socio-logic is located in the socially developed sense of practical reasoning, stemmed from communities of people who are thinking and acting together over time [1]. In other words, perpetual contact deals with the means to communicate and interact socially. This can be compared to the idea of perpetual motion concerning means of production that has driven the technological advancement of machinery in the past. However, in most cases of our daily life, perpetual contact cannot be always desirable as expected [9]. The availability can be affected by social roles, personal preferences and perceptions. The ability to refuse communication or resistance enables people to constrain the availability, or, in a broader sense, the perpetual contact. Mobile users, for example, can choose to limit accessibility by means of switching the phone off, letting calls go through to voice service, checking the incoming call's identification as well as blocking those who have their numbers. The use of mobile phone (and even mobile internet) can become constrained when telecom signal (or Wi-Fi) fails. In this sense, apparatgeist fails to capture the complexity of the mobile telephony.

\section{The Implication for Media Convergence}

Negroponte once states that "mass media will be redefined by systems for transmitting and receiving personalized information and entertainment in the next millennium" [10]. Holmes also argues that massive take-up of interactive media technologies, such as PCs and mobile telephony, proves individual's needs of finding connection in a computerized world [11]. Thus socio-logic of perpetual contact, rooted within the PCTs, challenge broadcast media in ways where individuals can become a producer, broadcaster and audience member to reflect the internet spirit of "Sharing". However the arrival of news forms of ICTs does not necessarily mean the demise of traditional media. They actually can be mutually constitutive. The content of broadcast media, for instance, can be distributed widely via more self-centered social networking websites; meanwhile, more and more audience can become participatory by tweeting their views to the program producers or posting them on the program website.

The use of any technology, from the perspective of apparatgeist, can be modified by users with certain social consequences and changes. Activists from online communities can use social media to get contacted and mobilize collective actions, as demonstrated by many social events in recent years. Thus traditional role of mass media as the instrument to maintain social order can be severely challenged. Regulators and policy makers may have to adjust themselves to these changes by facilitating dialogues or restricting the accessibility (and even banning its application). Social values, as reflected by the application of ICTs, can also vary due to the existing differences of political, economic and cultural system. Despite this, the symbolic meanings assigned by the New ICTs still empower people, especially those from grassroots backgrounds, to communicate more in a bottom-up manner.

\section{Conclusion}

With the ever-increasing convergence of ICTs, the concept "apparatgeist" proposed by Katz and Aakhus offers us an insightful perspective to explain the interactions between sophisticated technology 
and ever-complicated society [1]. Despite the limitations of perpetual contact in real life, the theory of apparatgeist helps us better understand both the function of technology and its relations to the social context and social network. As Katz argues, peoples' perception can lead to the feeling that the machine has a value or spirit and separate evolution unto themselves [8]. In this way, individual's relationship to the technology can be better explored with the reference to the social influence whereby their attitudes, perceptions and behaviors can be understood systematically.

\section{Acknowledgement}

The author is grateful to the Seed-corn Research Fund from Beijing International Studies University.

\section{References}

[1] J. E. Katz, M. Aakhus, Conclusion: Making meaning of mobiles-a theory of apparatgeist, in: J. E. Katz, M. Aakhus (Eds.), Perpetual Contact: Mobile Communication, Private Talk, Public Performance, Cambridge Press, Cambridge, 2002.

[2] J. Peters, Speaking into the air: A history of the idea of communication, University of Chicago Press, Chicago, 1999.

[3] R. Silverstone, Why Study the Media? SAGE Publications, London, 1999.

[4] M. Heidegger, The Basic Problems of Phenomenology, Indiana University Press, IN, 1975.

[5] M. Kotadia, Fiorina: Technology will disappear in 25 years, ZDNet Australia, 22 February 2006 http://www.zdnet.com.au/news/software/soa/Fiorina_Technology_will_disappear_in_25_years/0,2000 061733,39239611,00.htm (accessed 25 February 2006)

[6] S. W. Campbell and T. C. Russo, The social construction of mobile telephony: an application of the social influence model to perceptions and uses of mobile phones within personal communication networks, in Communication Monographs 70 (2003) 317-334.

[7] S. W. Campbell, Book review on perpetual contact,

http://www.com.washington.edu/rccs/bookinfo.asp?BookID=183\&ReviewID=216 (accessed 17 February 2006)

[8] J. E. Katz, Bodies, machines, and communication context: What is to become of us?, in: J. E. Katz (ed), Machines that become us: The social context of personal communication technology, New Brunswick, NJ, 2003, pp.311-319.

[9] G. Jessop, Mobile phones, driving and work: Current debates and historical reflections, in the Annual Meeting of the Australia and New Zealand Communication Association, Christchurch, New Zealand.

[10] N. Negroponte, Being Digital: the Road Map for Survival on the Information Superhighway, Hodder and Stoughton, London, 1995. 